\title{
História da Medicina
}

\section{O Exame Para Fellow of the Royal College of Surgeons of Edinburgh}

\author{
Hildo Rocha Cirne de Azevedo Filho iD \\ Universidade de Pernambuco, Pernambuco, Brasil
}

$凶$

Editado por

Juliana Ramos Andrade
Eu havia retornado da Inglaterra onde havia realizado meu treinamento na famosa The Radcliffe Infirmary da Universidade de Oxford. $\bigcirc$ meu mentor foi Mr. Christopher Adams, neurocirurgião dotado de rara maestria e com um profundo conhecimento de neurologia clínica, visto que houvera feito dois anos de treinamento no Serviço de Neurologia do renomado National Hospital for Nervous Diseases, popularmente conhecido como The Queens' Square. Adams teve como mestres Murray Falconer and Joe Pennybacher. É bom que se diga que naquele país, segundo a tradição, todo cirurgião é chamado de Mister apenas substituído quando se alcança o título de Professor, enquanto o Doctor é reservado para os clínicos.

Durante meu período em Oxford, além de terminar a minha formação, eu me vinculei a um projeto de pesquisa clínica que ensejou posteriormente a elaboração de uma tese intitulada Clinical Applications of Intracranial Pressure Monitoring que apresentei para obter o grau de Master of Science in Neurosurgery. No trabalho, a pressão intracraniana (PIC) era monitorizada no pós-operatório de cirurgias para clipagem de aneurismas intracranianos rotos e uma vez controlando a PIC se almejava reduzir os efeitos deletérios do vasospasmo cerebral, os quais em última instância são a isquemia, o edema e a hipertensão intracraniana. Na ocasião, comparei esse grupo com os resultados de uma série histórica e o grupo prospectivo apresentou resultados significantes melhores.

Dessa forma, portando um título universitário, faltava-me uma acreditação profissional, tipo revalidação da minha condição de neurocirurgião no Reino Unido, visto que eu vislumbrava me estabelecer do ponto de vista profissional definitivamente naquele país.

Todavia, isso não passava de um sonho porquanto a revalidação em lide significava a aprovação em várias provas que incluíam todas as especialidades cirúrgicas e que levaria à obtenção do grau de Fellow de um dos vários Colégios de Cirurgiões. Não havia um exame específico para neurocirurgia como, por exemplo, temos no nosso país quando nos apresentamos para a obtenção do título de especialista.

Dessa maneira, voltando ao Brasil em 1977, comecei a tentar montar um serviço no Hospital da Restauração do Recife nos moldes daquele que eu fora treinado em Oxford. Porém, as dificuldades materiais e de estrutura eram enormes e, além disso, eu me defrontava com a má vontade originada de neurocirurgiões mais antigos que não viam com bons olhos o aparecimento de 'novos concorrentes'. Apesar do hercúleo esforço desprendido, eu não estava satisfeito com o que estava conseguindo. Fortuitamente, em 1981, eu li na literatura neurocirúrgica britânica que, mudando todos os paradigmas anteriores e atuando de forma pioneira, o Royal College of Surgeons of Edinburgh estava iniciando um novel esquema de exames para qualificar especificamente neurocirurgiões. Foi uma inusitada quebra da tradição, a princípio mal recebida 
pelos outros Colleges uma vez que até então a obtenção do Fellowship era na área de cirurgia como um todo. Acredito que essa ideia inovadora se deveu à ação do Professor F. John Gillingham, então presidente do College, recentemente aposentado como professor de neurocirurgia da Universidade de Edimburgo e sucessor do Professor Norman Dott, antigo discípulo de Harvey Cushing. É dever mencionar que o Professor Gillingham viria a ser eleito Presidente Honorário da WFNS durante - Congresso Mundial de Neurocirurgia realizado em Toronto em 1985.

Como pré-requisito o candidato, nativo ou estrangeiro, deveria ter feito treinamento no Reino Unido ou na Irlanda e uma vez aprovado teria o seu diploma de neurocirurgião reconhecido naqueles países, podendo exercer integralmente a especialidade e aplicar consequentemente para postos de consultantes no sistema nacional de saúde como também para postos acadêmicos nas universidades. Logrando ser aprovado, e já tendo o título acadêmico pela Universidade de Oxford, era provável que eu viesse a conseguir definitivamente um emprego de neurocirurgião nas llhas Britânicas. Confesso que o meu desejo era conseguir tal posto em Oxford e assim retornando para onde eu ainda considerava a minha casa neurocirúrgica.

Como mencionado anteriormente, o Presidente do Colégio de Edimburgo era o Professor Gillingham, ressalte-se que o famoso professor era extremamente elegante no falar e no trajar, cortês e generoso para com os jovens neurocirurgiões. Ademais, devo dizer que foi um árduo esforço ser considerado apto para ser admitido no citado exame. Tive de coletar todos os documentos desde - curso de graduação, cópia do diploma de médico e os referentes aos anos que fizera em Recife, sem falar que era obrigatória tradução juramentada de toda a documentação.

Finalmente, em fins de 1982, recebi uma carta do Professor dizendo que eu fora aceito para ser examinado e que o mesmo teria lugar em setembro de 1983. O exame era dividido em dois dias, sessão de seis horas no primeiro e cinco no segundo, em 18 e 19 de setembro respectivamente. Recordo-me muito bem, visto que 19 era o dia do aniversário do meu saudoso pai.

Para isso, eu precisava me preparar bastante, rever as ciências básicas tais como anatomia, fisiologia, bioquími$\mathrm{ca}$, farmacologia e anatomia patológica. Era imperioso parar de trabalhar e ainda hoje não sei como eu pude arcar financeiramente com tais despesas, pois naquele ano já tínhamos três filhas.

Juntei o que pude, vendi umas cabeças de gado que tinha na fazenda dos meus pais e avós, e em início de julho fomos eu e Alita (minha esposa) para Oxford onde alugamos um pequeno apartamento da universidade para que eu pudesse estudar diuturna e adequadamente. Obviamente, passava parte dos dias úteis acompanhando as atividades rotineiras do meu antigo serviço, assistia ás cirurgias do 'Chefe' e frequentava assiduamente a biblioteca.

Uma semana antes do exame, alugamos um pequeno carro e zarpamos para Edimburgo. O sempre lembrado Professor Douglas Miller, que havia substituído na cátedra e na chefia do serviço o Professor Gillingham, tinha certa afeição por mim mercê eu ter frequentado nos anos anteriores alguns cursos do Conselho Britânico naquela cidade e muito gentilmente conseguiu que ficássemos em um alojamento universitário porque ainda era época das férias acadêmicas. Lembro que o alojamento era extremamente frio, o banheiro mais ainda e para aumentar o desconforto ficava algo distante do nosso quarto. Segundo o costume britânico, o frio se explicava em razão de ser ainda verão e por via de consequência o aquecimento do edifício deveria permanecer desligado.

Como referi acima, apesar de ser verão, Edimburgo embora bastante bonita e clássica, com seus majestosos prédios góticos e tendo o castelo no alto do morro como testemunha de centenas de anos de guerras, massacres, assassinatos e destituição de monarcas, apresentava-se como sempre fria, chuvosa, cinzenta e o vento cortava a alma quando se atravessava uma daquelas pontes que passam sobre o vale.

O Royal College of Surgeons of Edinburgh, localizado na Nicolson Street, continuação da North Bridge, é uma edificação imponente, até certo ponto sombria e impressiona pela majestade das suas colunas e da sua arquitetura, refletindo e guardando mais de quatro séculos de história da cirurgia. O primeiro dia do exame teria lugar na Western General Infirmary e o College abrigaria o segundo e último dia do exame. Fiquei extasiado ao adentrar naquele cenáculo sagrado da cirurgia mundial, depositário do passado glorioso da medicina desde que houvera sido fundado em 1505, no entanto o prédio atual projetado por William Playfair, o mais famoso arquiteto escocês da época, só fora inaugurado em 1832. Com profundo respeito e admiração vislumbrei os retratos pintados a óleo de ex-presidentes e antigos fellows como Charles Bell, John Barclay, Joseph Lister e os Monros. Eu tinha sido aconselhado visitar o museu e apreciar as centenas de peças anatômicas ali colecionadas, porque algumas poderiam fazer parte do exame. Perdi meu tempo, nenhuma delas foi utilizada.

A primeira fase do exame como mencionei teve lugar nas enfermarias de neurocirurgia da Western General Infirmary, departamento então dirigido pelo Professor Douglas Miller. O tempo total era de seis horas divididas em várias sessões em que examinávamos os pacientes, discutíamos os casos com os examinadores que nos faziam perguntas sobre achados clínicos, radiológicos e condutas. Eram 10 os examinadores, recordo-me de alguns, lembro bem do Professor Gillingham, sempre gentil e educado para com aqueles oito jovens com faces de apavorados. Douglas Miller era prático e objetivo, sempre ligado em problemas correlacionados com o trauma, com a metabologia cerebral, com a hipertensão intracraniana e com o fluxo sanguíneo cerebral. Philip 
Harris se interessava pelas afecções da coluna vertebral e para ele foram reservados os casos de patologia cervical. Parecia sempre mal- humorado, pletórico e como se estivesse tendo uma crise hipertensiva.

John Garfield viera de Southampton, parecia ácido com perguntas complexas e de difícil resposta. No meio da sua inquisição me perguntou onde eu houvera sido treinado e quem era o meu mentor. Quando respondi que tinha sido Chris Adams em Oxford, ele fechou a cara e se tornou mais difícil ainda. Nessa ocasião temi pelo meu destino. Depois eu soube que ele e Adams não tinham a melhor das relações.

Tive a alegria de ser examinado por Huw Griffith, então chefe do serviço em Bristol, um dos neurocirurgiões mais brilhantes que conheci e que infelizmente morreu aos 63 anos de uma doença neoplásica fulminantemente agressiva, tendo a sua partida precoce feito muita falta à neurocirurgia britânica. As perguntas de Huw eram inteligentes e faziam você se sentir como se estivesse discutindo um caso na enfermaria e não participando de um exame tão importante, no qual o resultado final era simplesmente, sim ou não.

O Professor Bryan Jennett viera de Glasgow, brilhante clínico e detentor de uma exuberante cultura neurológica e neurocirúrgica. Ele obtivera parte do seu treinamento em Oxford, sob a direção de Joe Pennybacher. Todavia, Jennett era um neurocirurgião reconhecidamente conservador que às vezes parecia mais apreciar a manipulação dos números e dados estatísticos relativos aos traumatismos crânio-encefálicos do que enfrentar as longas e penosas horas nas salas cirúrgicas. Durante a sua arguição comigo aconteceu um fato interessante, foi sorteado para que eu examinasse uma moça jovem, nos seus 30 anos, com severa e incapacitante lombociatalgia, sobretudo aos esforços e rebelde ao tratamento conservador. Havia um sinal de Lasègue baixo, apresentava - reflexo aquileu abolido e déficit sensitivo no território de S1. Enfim, um quadro clássico de uma hérnia discal lombar, confirmado pela mielografia visto que não havia ressonância magnética naquela época. Após analisar todos os detalhes do caso recomendei tratamento cirúrgico. O Professor conservadoramente retrucou: 'mas você vai operar uma $P E$ ?' $^{\prime} O$ que será $P E$ pensei eu. Naquele momento, eu já não podia consultar o prontuário da paciente para saber que acrônimo seria esse. Novamente, Jennett enfatizou: operar uma PE? David Mendelow, à época senior lecturer em Edimburgo, antes de ser professor em Newcastle, assistindo o exame por detrás do professor me forneceu a valiosa informação: PE is physical educator, ou seja, professora de educação física. Nesse momento, tentei contornar dizendo: sendo uma $P E$ vamos dar um pouco mais de tempo com o tratamento conservador para ver se evitamos a cirurgia. Acho que consegui me safar! O segundo paciente com o Professor Jennett foi uma paciente do sexo feminino com um aneurisma paralítico da comunicante posterior, que já fora operada, estava bem e o exame neurológico apenas demonstrava a paralisia completa do $3^{\circ}$ nervo que já estava presente no pré-operatório, fato que ensejara o seu internamento. Pergunta do professor: você acha que ela vai recuperar completamente os movimentos desse olho? Com a certeza peculiar àqueles ainda sem muita experiência eu respondi: em 90 dias ela estará totalmente normal com todos os movimentos oculares recuperados. Retrucou então o sábio professor, 'teste sempre o olhar vertical para cima, ele nunca retorna'. E disse ainda, 'em provas também se aprende'! Fantástica informação, ao longo de todos esses anos eu só presenciei uma vez em casos semelhantes que o olhar vertical para cima houvesse retornado total ou parcialmente.

O segundo dia do exame teve lugar no prédio do College, mais precisamente nas enormes dependências do museu que naquele dia parecia mais sombrio e assustador do que a impressão que sentira quando o visitara alguns dias antes.

A prova constava de cinco etapas de 60 minutos com dois examinadores por cada bloco, tendo o tempo rigidamente controlado por um relógio que preguiçosa e lentamente teimava em não atingir o tempo estipulado no regulamento. Os blocos constavam dos seguintes temas: neuroanatomia, neurofisiologia e neurofarmacologia, neuroanatomia patológica, discussão sobre entidades nosológicas e técnicas cirúrgicas, e por fim tratamento não cirúrgico das patologias neurocirúrgicas.

A prova de neuroanatomia transcorreu sem maiores problemas com a análise de várias peças anatômicas colocadas em cima de uma mesa, com ênfase à substância branca e perguntas ligadas a acessos e condutas.

Contudo, a prova de neurofisiologia e neurofarmacologia foi extremamente dura e difícil. Os examinadores eram os Professores Edward Hitchcock e John Hankinson, ambos profundos conhecedores dos temas em lide visto que eram experts na neurocirurgia funcional. Hitchcock houvera feito parte do seu treinamento em Oxford e em Londres, antes de ser senior lecturer em Edimburgo, tendo posteriormente alcançado o honroso título de professor de neurocirurgia em Birmingham. Hankinson era professor de neurocirurgia em Newcastle e nunca me esqueço do seu sorriso franco e da sua gravata borboleta que gostava de usar com frequência. $E$ as perguntas não paravam, Hitchcock queria saber em profundidade o funcionamento do sistema neuromuscular e se fixou demoradamente sobre tudo que dizia respeito ao muscle spindle e eu pensava: meu Deus, esse relógio não anda! Felizmente, os 60 minutos se passaram e fui encaminhado para outra dupla que iria me arguir na área de neuroanatomia patológica.

A prova constava de uma série de lâminas projetadas, para que descrevêssemos os aspectos histológicos e posteriormente emitíssemos o diagnóstico da patologia. Em algumas ocasiões, dados clínicos do paciente eram fornecidos o que obviamente ajudava na elaboração da resposta. Guardo bem na memória um caso típico de glioblastoma multiforme que diagnostiquei assim que o slide foi apresentado, porém fiquei mais tempo do que 
deveria descrevendo pormenorizadamente as suas várias nuances, pois tinha receio de não saber diagnosticar a próxima lâmina a ser projetada. Nesse momento, um dos examinadores disse sorrindo, provavelmente atento que eu estava fazendo 'cera': já notamos que você reconhece essa patologia, vamos passar para o outro slide. Finalmente, mais 60 minutos se foram.

A quarta fase do exame foi tranquila e saí com a esperança que houvera me saído bem.

A quinta e última versava sobre: condutas não cirúrgicas das patologias neurocirúrgicas. Os examinadores eram Huw Griffith de Bristol e um senhor anestesista de Sheffield, cujo nome não me recordo, o qual era chefe da unidade de terapia intensiva, e que anos depois fiquei sabedor que ele tinha cometido suicídio se enforcando no dia de Natal. Huw Griffith tinha alguma consideração e até simpatia pela minha pessoa, eu acredito, tanto é que em 1987 me colocou como membro do primeiro Editorial Board do British Journal of Neurosurgery, por ele idealizado e fundado naquele ano. Huw era o mentor do melhor amigo que fizera durante o meu treinamento em Oxford e até hoje mantemos nossa amizade, Michael Torrens, considerado seu possível sucessor em Bristol, mas que abdicou e resolveu se mudar para Atenas em virtude de ter se casado com uma neuroanestesista grega.

Pois bem, o anestesista gostava muito do tema monitorização da pressão intracraniana. Então ele falou, vamos começar discutindo monitorização da PIC. Griffith de imediato retrucou, eu não permito que esse assunto seja a ele perguntado uma vez que foi tema da sua tese apresentada à Universidade de Oxford há sete anos e como tal ele deve saber bastante do assunto. Humildemente e com voz quase imperceptível eu ousei falar: this is not fair, Sir. Todavia, mais que rapidamente eu reorganizei minhas ideias e racionei que estava aprovado. Se eu estivesse ameaçado de não passar no exame, Huw certamente não cometeria essa injustiça de me prejudicar, o que ele queria naquele momento era saber mais da minha erudição e conhecimento. Com efeito, 10 examinadores reunidos durante dois dias em um hotel já deveriam quase que formado um consenso de quem deveria ser reprovado ou não.
Terminadas as cinco horas de exame, exaustos, fomos os oito encaminhados para a antessala do gabinete do Presidente a fim de ouvirmos o resultado a ser anunciado pelo secretário do College, o qual apareceu trajado com uma vestimenta quase medieval e graças a Deus eu estava entre os três que haviam sido aprovados. Os cinco reprovados quase que foram enxotados pela porta lateral.

Adentramos então no impressionante gabinete do Presidente, no caso o Professor Gillingham, que estava com o majestoso e tradicional traje que os presidentes vêm usando há mais de 200 anos, acompanhado pelos examinadores e vários membros da diretoria. Tudo não durou mais do que 10 minutos, foi nos oferecido um cálice de sherry, o presidente nos parabenizou e informou que a cerimônia oficial de entrega dos diplomas ocorreria dois meses após em um jantar de gala. Infelizmente, por dificuldades financeiras não pude voltar a Edimburgo para esse evento oficial, tendo posteriormente recebido o valioso diploma pelo correio, que guardo como uma das mais importantes relíquias da minha carreira profissional.

Naquela noite, extremamente gelada, Alita e eu comemoramos a nossa vitória, bebendo uma quantidade de vinho que nunca havíamos ingerido, com um lindo jantar à luz de velas em uma dos melhores restaurantes da High Street, cuja continuação leva ao Castelo, o qual feericamente iluminado parecia mais bonito e imponente do que nunca.

Com muita tranquilidade enfatizo que, avaliando posteriormente todos os aspectos, prevaleceu o bom senso, o amor à família e ao meu Pernambuco, quando mesmo obtendo o título e revalidando o diploma naquele país, resolvi me instalar definitivamente no meu Recife, e como tal ser protagonista do progresso da medicina e da neurocirurgia na minha região.

Achei por bem relatar esse fato, tão importante para mim e para a minha família, que mobilizou tantos sacrifícios inclusive de ordem financeira, não para o gáudio pessoal, mas prioritariamente para reconfirmar o que certa feita foi dito pelo Professor Euríclides de Jesus Zerbini: 'NADA RESISTE AO TRABALHO'. 